\title{
INFLUENCE OF CHANGES IN DISSOLVED OXYGEN CONTENT ON FISH BEHAVIORAL TRAJECTORIES DURING WATER EUTROPHICATION
}

\author{
HUANG, Y. Q. ${ }^{1,2,3}-$ CAI, D. S. $.^{1,3 *}-$ LI, M. Q. ${ }^{1}-$ WU, T. H. ${ }^{2}-$ WU, P. G ${ }^{1,3}-$ LI, L. ${ }^{1,3}$ \\ ${ }^{1}$ College of Civil Engineering and Architecture, Guangxi University, 530004 Nanning, China \\ ${ }^{2}$ Guangxi Key Laboratory of Environmental Pollution Control Theory and Technology, Guilin \\ University of Technology, 541004 Guilin, China \\ ${ }^{3}$ Guangxi Water \& Power Design Institute, 530023 Nanning, China \\ *Corresponding author \\ e-mail: caidesuo@vip.163.com
}

(Received 30 ${ }^{\text {th }}$ Sep 2018; accepted $29^{\text {th }}$ Nov 2018)

\begin{abstract}
Fish is an important organism in the water and its living environment are a unified whole, interrelating and influencing each other. Changes in fish behavioral trajectories can directly reflect the deterioration degree of water. When the cyanobacteria in the water consume a lot of oxygen during reproduction, death and decomposition, which makes the dissolved oxygen content rapidly decrease, the fish swimming trajectory changes significantly and responds accordingly. In this paper, acoustic tag tracking technology was used to study the swimming ability of fish by simulating the eutrophication process in a simulating natural ecosystems tank and obtain its three-dimensional trajectory to determine the dissolved oxygen threshold when fish behavior changed. The variation regularity of fish behavioral trajectories was investigated with the change of dissolved oxygen content during water eutrophication. The experimental results showed that the individual behavioral response of adult carp was unobvious in the process of oligotropher to light eutropher, but at the state of middle and hyper eutropher was obvious. When the dissolved oxygen is $0.5 \mathrm{mg} / \mathrm{L}$, adult carp began to breathe hard and float on the water surface. When the dissolved oxygen content dropped to $0.2 \mathrm{mg} / \mathrm{L}$, adult carp began to die. During the process of dissolved oxygen content decreasing, the swimming trajectory of adult was convergent in space while they migrated from the bottom of water to surface in the direction of longitudinal water depth, and the swimming speed was slower and slower. Regression analysis was used to analyze the correlation between individual behavioral trajectories of adult carp and dissolved oxygen content. The results indicated that the swimming trajectory of water depth was highly negatively correlated with dissolved oxygen content. The swimming speed of adult carp and dissolved oxygen content had a strong negative correlation. The significant changes in the individual behavioral trajectories of adult carp indicated the environment of water has changed. It was suggested that dissolved oxygen content, which affected the changes of fish behavior, and individual behavioral trajectories of fish as a biological indicator were used to evaluate the water ecological restoration effect and ecological health status of water. It can more accurately reflect the current status of the aquatic ecosystem.
\end{abstract}

Keywords: acoustic signal monitoring technology, individual behavioral trajectories of fish, the dissolved oxygen threshold, correlation, water eutrophication

\section{Introduction}

It caused algae and other plankton in water to rapidly multiply, died and decomposed when massive pollutants containing nitrogen and phosphorus nutrients were discharged. Especially in the period from June to September of each year, the water temperature rises and the light intensity increases. It is suitable for cyanobacterial cell division, growth and consumption of a large amount of oxygen, which causes the dissolved oxygen content in water to decrease rapidly. At this time, it is difficult for the 
cyanobacteria to complete the normal metabolic process. Then, it is decomposed by microorganisms and decayed. Water quality deteriorated. Aquatic organisms and fish began to die. It was known as "ecological cancer" (Gong, 2006).

The oxygen in the water is mainly derived from air and photosynthesis of aquatic plants, which directly affects the living environment of aquatic organisms. As an important aquatic organism in water, fish relies on obtaining oxygen from water to carry out various physiological activities, and its behavior has a certain relationship with the change of dissolved oxygen content in the water. When the water environment changes, the fish needs to consume a certain amount of energy to adapt the new environment whose energy source needs to be maintained by the dissolved oxygen in the water. Once the water lacks of oxygen, the changes of fish's physiological characteristic and behavior were showed firstly. Fish floated on the water surface and died.

Fish locates on the top of the food chain as an advanced group of aquatic organisms. It can objectively reflect the biological state of water environment, which is a good representation. So, fish is a living "monitor" for water pollution. There are dozens of fishes monitoring materials such as carp, grass carp, silver carp, bighead carp and crucian distributed in most of lakes and reservoirs. Many reports mentioned that carp (Cyprinus carpio) was used as a monitoring indicator species to study the effects of changes in water environment on their physiology and behavior. For example, Sakalli studied the effects of sewage treatment plant effluents on hepatic and intestinal biomarkers in common carp (Sakalli et al., 2018). The effects of water-borne lead on the swimming capability and metabolism of juvenile grass carp, critical swimming speed and oxygen consumption rate were measured in water with four concentrations of $\mathrm{Pb}^{2+}$ (Zhu et al., 2018).

At present, the monitoring methods of fish behavior used mainly video, image observation and computer simulation technology. Kang et al. used two cameras for tracking the fish behavior in three dimensional data. The 3D data were analyzed for fish behavior such as, swimming speed and surfacing behavior (Kang et al., 2009). Huang et al. studied the behavioral responses of zebrafish under the combination effects of cypermethrin and deltamethrin, a set of motion activities were monitored and analyzed using a computer-imaging technique (Huang et al., 2009). Behavioral variations of fish populations are difficult to measure quantitatively. To quantify such measurements, Vassilis et al. developed a low-cost computer vision system to analyze small fish populations' behavioral variations in aquaculture tanks (Papadakis et al., 2012).

It can obtain the fish swimming behavior characteristics including fish movement speed and acceleration, which relate to water quality by using the computer vision technology in fish movement behavior monitoring (Zhou, 2009; Zhang, 2012; Huang et al., 2017; Yan et al., 2018). It can record the behaviors of fish population to achieve online monitoring and early warning of water quality by using computer vision and video tracking technology (Liao, 2012; Huang, 2014). Image processing technology was combined with computer programming to process the fish motion video. It could simulate the fish trajectories, directly draw the fish's motion trajectories on the video image and realized the real-time tracking (Jiang, 2015).

Although video, image observation and computer simulation techniques are usually used to analyze fish behavior, but the data processing is very difficult and the error is big. It is difficult to obtain quantitative indicators of fish behavioral trajectories. In recent years, acoustic monitoring technology has been gradually applied to fish resource detection and behavior monitoring. Acoustic tracking technology has gradually become 
the most important means to monitor the behavior of aquatic animals. For example, it can get the fish swimming speed, migration times, residence time, the changes of habitat and spawning grounds during fish migration by this technology to fish migration monitoring (Steig and Johnston, 2010; Skalski et al., 2012; Pinnix et al., 2013; Teo et al., 2013). Acoustic tag tracking technology was used to obtain fish behavioral trajectories, some physical and mathematical models were established (Cai and Li, 2012; Romine et al., 2014). Acoustic tag tracking technology is used to evaluate the behavior, survival and behavior changes of fish in the ecosystem (Everson et al., 2013; Schultz et al., 2015; Hollo et al., 2017).

In summary, it can see that the acoustic tag tracking technology is mainly used in fish habits, migration, fish stock, fish species protection and habitat restoration. There are few reports on the application of fish behavioral trajectories to the ecological environment. Therefore, in this study, acoustic tag tracking technology was used to study the swimming ability of fish by simulating the eutrophication process in a simulating natural ecosystems tank, and obtain its three-dimensional trajectory to determine the dissolved oxygen threshold when fish behavior changed. The correlation between fish individual behavioral trajectories and dissolved oxygen content was analyzed, which provided a reliable reference for evaluation of ecological restoration effect and ecological health status of water.

\section{Materials and methods}

\section{Water eutrophication simulation experimental tank}

Water eutrophication status of lakes and reservoirs can be divided into three types: oligotrophy, mesotrophy and eutrophy (Xu and Jiang, 2009). Experiment was carried out by simulating these three eutrophic statuses of natural waters. The length, width, height of simulation experimental tank is $3 \mathrm{~m} \times 1 \mathrm{~m} \times 1 \mathrm{~m}$; water depth is $0.75 \mathrm{~m}$; the thickness of tank substrate is $0.15 \mathrm{~cm}$. The tank substrate is consisted of lake sediment, aquatic plants and common aquatic organisms such as fish, shrimp, crabs, snails and loach (Fig. 1). The tank was equipped with diving light for simulating lighting, residual chlorine device and water level meters. The water used in the simulated experimental tank is tap water. The concentration of residual chlorine is reduced by aeration to less than $0.02 \mathrm{ppm}$ which is harmless to fish.

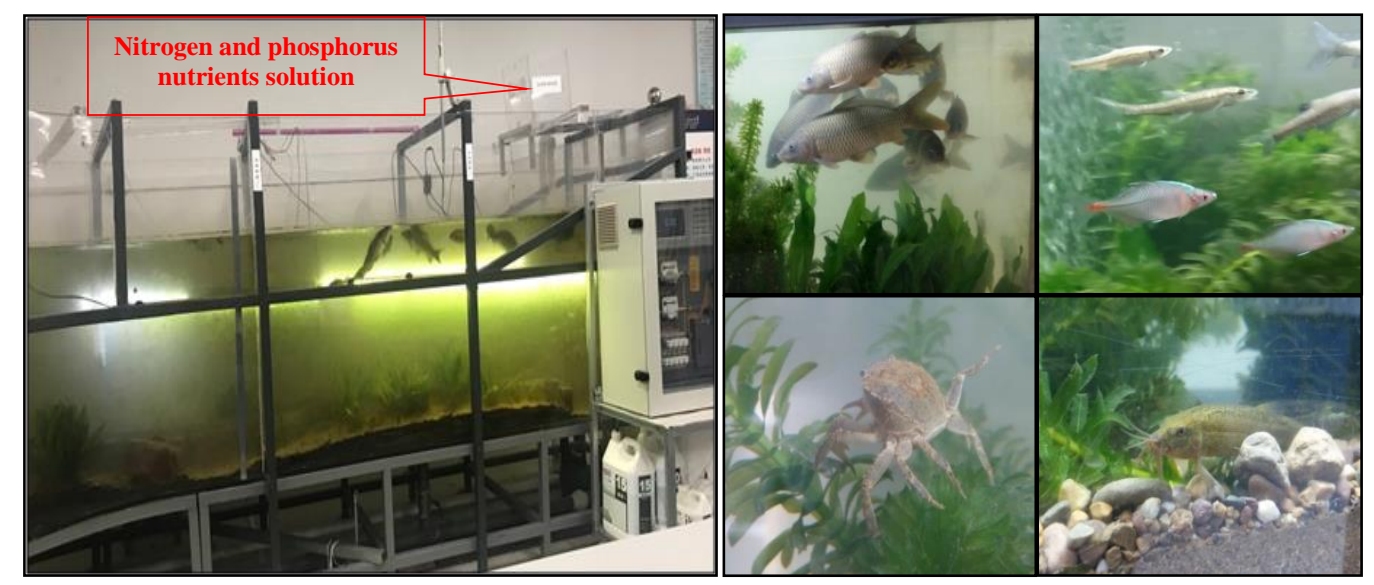

Figure 1. Experimental tank and ecological structure community taken from lake 


\section{Experimental fish selection and domestication}

In this experiment, five healthy and lively adult carps with a length of $15 \mathrm{~cm}-20 \mathrm{~cm}$ and a body weight of about $0.5 \mathrm{~kg}-1.0 \mathrm{~kg}$ was selected. Five activated acoustic tags were activated and transplanted to these fishes (Fig. 2). The transmission frequencies of five tags are set from $3100 \mathrm{~Hz}$ to $3500 \mathrm{~Hz}$. It means that the tags emit an acoustic signal every 3 seconds. After these fishes were domesticated in the tank for one month to adapt the water environment, the simulation experiment of water eutrophication began. At this time, the water was in the oligotrophic stage.
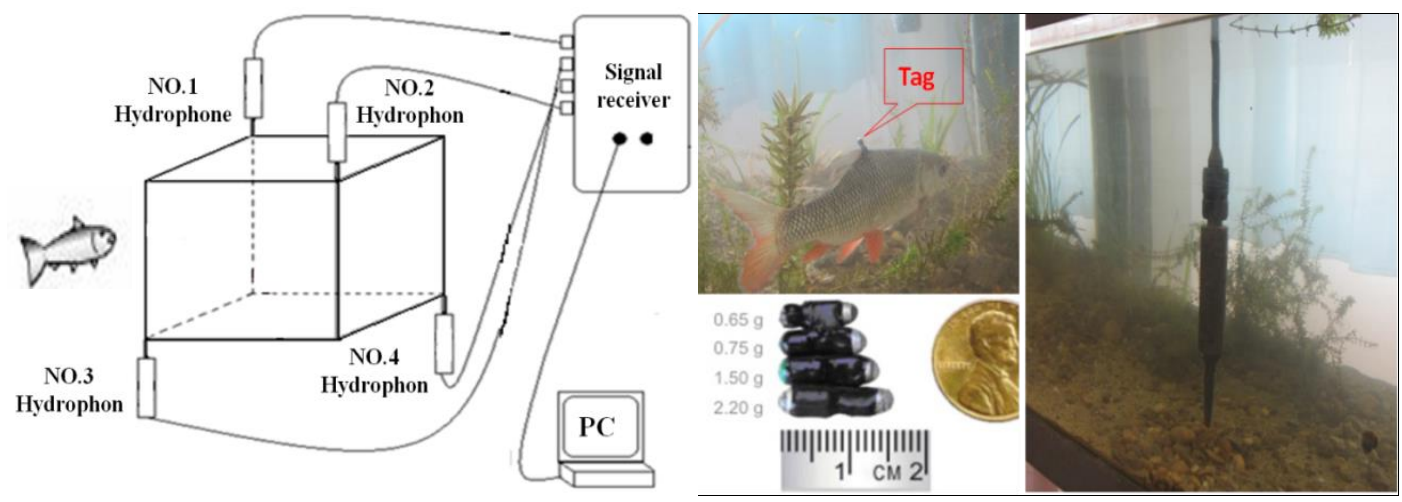

Figure 2. Principle of fish behavioral trajectories monitoring

\section{Experimental method}

\section{Preparation of nitrogen and phosphorus nutrient solution}

According to water volume in the tank, an appropriate amount of ammonium phosphate was prepared into nitrogen and phosphorus nutrient. The $\mathrm{pH}$ value in nutrient solution was reduced after aerating for 48 hours. The nitrogen and phosphorus nutrient solution has $\mathrm{pH}$ of 6.85 , conductivity of $1354.6 \mu \mathrm{s} / \mathrm{cm}$, ammonia nitrogen concentration of $180.0 \mathrm{mg} / \mathrm{L}$, total phosphorus concentration of $120.0 \mathrm{mg} / \mathrm{L}$, and total nitrogen concentration of $202.8 \mathrm{mg} / \mathrm{L}$.

\section{Discharge of nitrogen and phosphorus nutrient solution}

Nitrogen and phosphorus nutrients were discharged according to the evaluation criteria and classification of lake and reservoir in the Technical Regulations for Surface Water Resources Quality Assessment, Lake (reservoir) Eutrophication Evaluation Method and Grading Technical Regulations (China National Environmental Monitoring Center) and the US Environmental Protection Agency (USEPA) (Zhai et al., 2009).

The nitrogen and phosphorus nutrient solution are discharged in a steady flow of $0.10 \times 10-6 \mathrm{~m} 3 / \mathrm{s}$, and increased or decreased the amount of solution in the water according to the consumption. It makes the water environment in different nutritional state. Different ecological behavior of fish at each stage is monitored in particular when the environment is in the critical nutritional state. The process of the effect of oxygen consumption on fish behavior during the water eutrophication is shown in Fig. 3. 


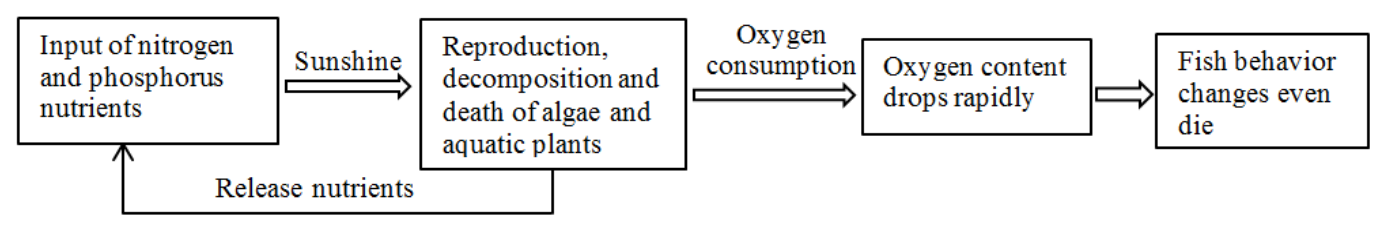

Figure 3. The process of water eutrophication simulation

\section{Monitoring methods and techniques}

\section{The methods of water quality monitoring}

Water quality monitoring uses two methods: online monitoring and sampling analysis. Water quality monitoring indicators include total phosphorus, total nitrogen, chlorophyll-a, potassium permanganate index, transparency and dissolved oxygen content, which affect water eutrophication and the living environment of fish. Chlorophyll-a, transparency and dissolved oxygen content were monitored by algae detector (Model algae-wader), turbidity meter (Model 2100Q) and dissolved oxygen meter (Model multi 3410). Total phosphorus, total nitrogen and potassium permanganate indexes were sampled and analyzed according to the standard methods.

\section{Fish behavior trajectory monitoring technology}

The fish behavior track is monitored by acoustic signal technology, which uses four hydrophones to receive the sound waves transmitting from the acoustic tags transplanted to the fishes. The raw signal is transmitted to PC terminal for signal processing through the data lines (Fig. 2). Two-dimensional or three-dimensional behavioral trajectories of fish can be obtained after denoise processing by PC. Thereby, 2D and 3D behavioral trajectories of fish can be monitored in real-time. The individual behavioral trajectories of fishes are monitored by HTI Model 291 acoustic tag system.

\section{Experimental data processing method}

According to the transmission frequency of tag signal, a swimming trajectory point of fish is obtained every three seconds. So a set of data has 1200 trajectory points, which automatically save every one hour. The time of experiment was from February to October 2018 (nine months). The swimming trajectory points of one fish were $7.776 \times 10^{4}$. After data cleaning such as de-noising and abnormal data elimination, the track points have about $5 \times 104$. In this study, some representative data were processed and analyzed.

Regression analysis is one method of data mining, which was used to determine the quantitative relationship between two or more variables (Wu, 2017). In order to find the correlation between dissolved oxygen content and fish behavioral trajectories from these huge experimental data, the method was used in the paper.

Correlation analysis refers to the relationship between a variable $\mathrm{x}$ and another variable $\mathrm{y}$, and the quantitative description of $\mathrm{x}$ and $\mathrm{y}$. To determine the correlation between the two variables, a bivariate correlation analysis can be used. The correlation coefficient, this statistical indicator, is used to reflect the correlation and the degree of closeness between two variables. It is calculated by product-moment correlation. Therefore, the correlation coefficient is also called linear correlation coefficient or 
product difference correlation coefficient, which is represented by the symbol " $\mathrm{r}$ ". The range of " $r$ " value is between -1 and +1 .

It is used to measure the linear relationship between two variables. It is positive correlation when " $r$ " is more than 0 , while it is negative correlation when " $r$ " is less than 0 . The two variables are irrelevant correlation when " $r$ " is 0 . The more greater of absolute value of " $r$ ", the higher correlation of two variables. According to the absolute value of " $\mathrm{r}$ " can be divided into: $0.8<\mathrm{r}<1.0$ is extremely strong correlated, $0.6<\mathrm{r}<0.8$ is strongly correlated, $0.4<\mathrm{r}<0.6$ is moderately correlated, $0.2<\mathrm{r}<0.4$ is weakly correlated, $0.0<\mathrm{r}<0.2$ is extremely weakly correlated or not correlated.

SPSS 22.0 analysis software is used to process the data. The correlation coefficient is calculated according to the statistical formula of Pearson correlation coefficient (Zhang, 2003; $\mathrm{Wu}, 2017)$ :

$$
r=\frac{\sum x y-\frac{\sum x \Sigma y}{N}}{\sqrt{\sum x^{2}-\frac{(\Sigma x)^{2}}{N} \sqrt{\sum y^{2}-\frac{(\Sigma y)^{2}}{N}}}}
$$

\section{Analysis of experimental results}

\section{Changes in water quality indicators during water eutrophication}

Some water quality indicators such as total phosphorus, total nitrogen, chlorophyll-a, permanganate index, transparency and dissolved oxygen were monitored in the process of water eutrophication. The changes of indicators at each stage are shown in Table 1.

Table 1. Monitoring results of water quality indicators in the process of eutrophication

\begin{tabular}{|c|c|c|c|c|c|c|c|}
\hline $\begin{array}{c}\text { Nutritional } \\
\text { status } \\
\text { classification }\end{array}$ & $\begin{array}{l}\text { Monitoring } \\
\text { time }\end{array}$ & $\begin{array}{c}\text { Total } \\
\text { phosphorus } \\
(\mathrm{mg} / \mathrm{L})\end{array}$ & $\begin{array}{c}\text { Total } \\
\text { nitrogen } \\
(\mathrm{mg} / \mathrm{L}) \\
\end{array}$ & $\begin{array}{c}\text { Chlorophyll-a } \\
(\mathrm{mg} / \mathrm{L})\end{array}$ & $\begin{array}{c}\text { Permanganate } \\
\text { index } \\
(\mathrm{mg} / \mathrm{L}) \\
\end{array}$ & $\begin{array}{c}\text { Transparency } \\
\text { (m) }\end{array}$ & $\begin{array}{c}\text { Dissolved } \\
\text { oxygen } \\
(\mathrm{mg} / \mathrm{L}) \\
\end{array}$ \\
\hline Oligotropher & Feb., 2018 & 0.003 & 0.025 & 0.0015 & 0.35 & 7.50 & $6.0-7.5$ \\
\hline Mesotropher & $\begin{array}{c}\text { From Mar. to } \\
\text { Apr.,2018 }\end{array}$ & 0.045 & 0.46 & 0.0073 & 2.86 & 2.75 & $4.0-6.0$ \\
\hline $\begin{array}{c}\text { Light } \\
\text { eutropher }\end{array}$ & $\begin{array}{c}\text { From May. to } \\
\text { Jun.,2018 }\end{array}$ & 0.13 & 1.12 & 0.022 & 8.12 & 0.48 & $2.0-4.0$ \\
\hline $\begin{array}{c}\text { Middle } \\
\text { eutropher }\end{array}$ & $\begin{array}{l}\text { From Jul. to } \\
\text { Aug., } 2018\end{array}$ & 0.45 & 5.65 & 0.125 & 24.8 & 0.36 & $0.5-2.0$ \\
\hline $\begin{array}{l}\text { Hyper } \\
\text { eutropher }\end{array}$ & $\begin{array}{c}\text { From Sep. to } \\
\text { Oct.,2018 }\end{array}$ & 1.45 & 16.8 & 1.33 & 55.3 & 0.15 & $<0.5$ \\
\hline
\end{tabular}

\section{Analysis of changes in fish behavioral trajectories during water eutrophication}

Fish had a short-term avoidance behavior from pollution sources during the emission of nitrogen and phosphorus nutrients solution. When the concentration of water quality factors in the water environment was balanced, the fish returned to the original behavioral trajectories. It indicated that the fish is sensitive to the change in water environment, but their adaptability is relatively strong. The monitoring results show that the behavioral trajectories of fish in three stages (oligotropher, mesotropher and eutropher) are quite different (Fig. 4). At the oligotrophic stage, the fish swam back and forth, and their behavioral trajectories were wide range; the behavioral trajectories of 
fish at mesotrophic stage was characterized by preference for activities in a certain area, and the behavioral response was relatively slow; in the eutrophic stage, the fish basically gathered somewhere and didn't not move. It indicated that with the change of pollutant concentration in water, the fish had avoidance behavior, they swam slowly because of hypoxia, and their response to external disturbance was not sensitive.

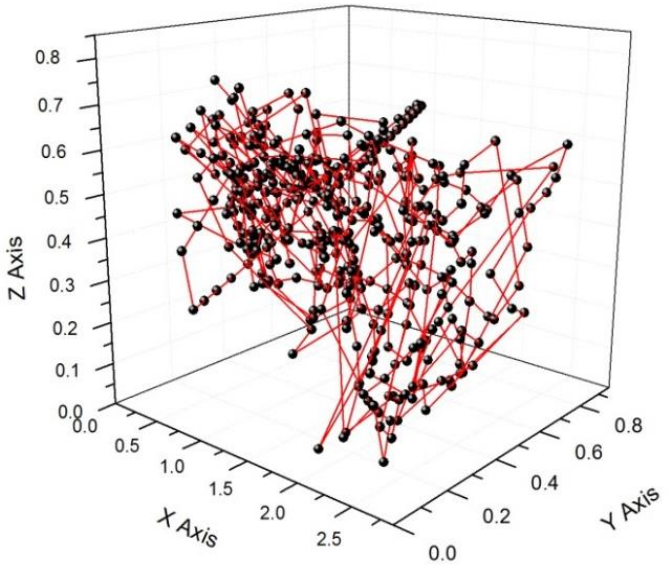

(a) Fish behavioral trajectories in the oligotrophic stage (Feb., 2018)

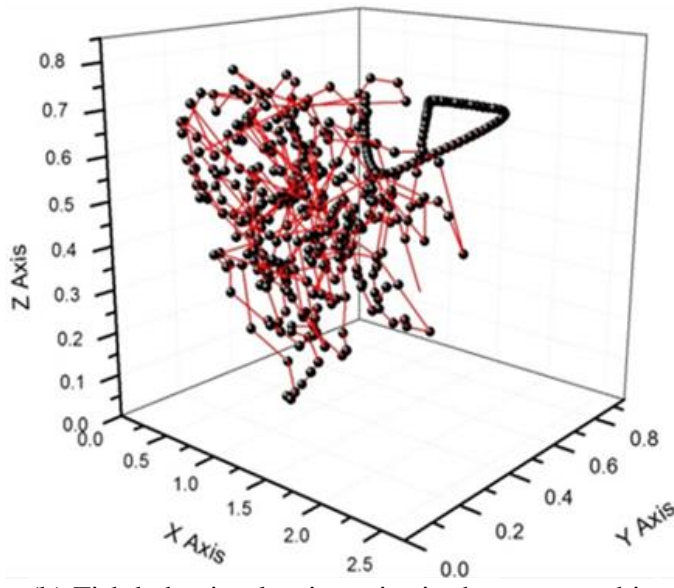

(b) Fish behavioral trajectories in the mesotrophic stage

(From Mar. to Apr., 2018)

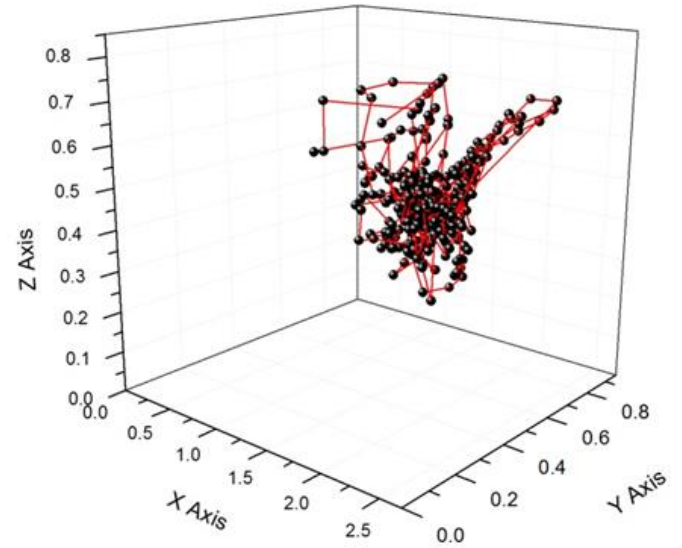

(c) Fish behavioral trajectories in the eutrophic stage (From May. to Oct., 2018)

Figure 4. Three-dimensional behavioral trajectories of carp during water eutrophication

\section{Influence of dissolved oxygen content change on fish behavioral trajectories}

The decrease of dissolved oxygen content not only affects the activity of aquatic organisms, but also indirectly controls the degradation of cyanobacterial toxins. The behavior of fish will also change, and the behavioral responses expressing in various nutrient stages are significantly different. The performance is as follows:

1) The dissolved oxygen content was $6.0 \mathrm{mg} / \mathrm{L}$ to $7.5 \mathrm{mg} / \mathrm{L}$ in oligotrophic stage. At this stage, the carp behavioral trajectories were scattered. They swam back and forth in the water according to their living habits and preferences (Fig. 5a). 


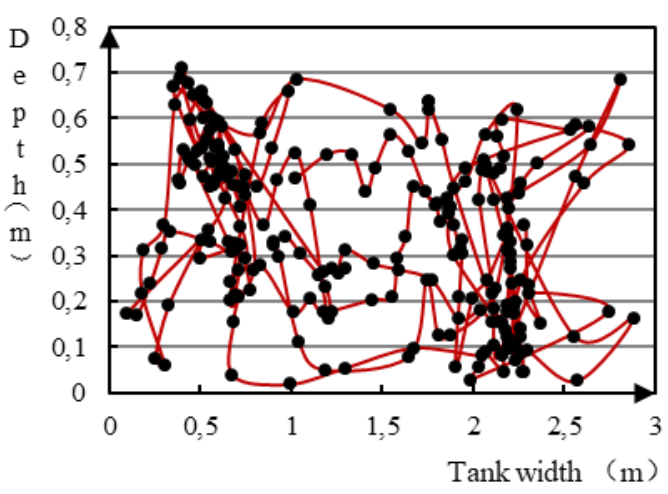

(a) Dissolved oxygen content was 6.0-7.0 $\mathrm{mg} / \mathrm{L}$

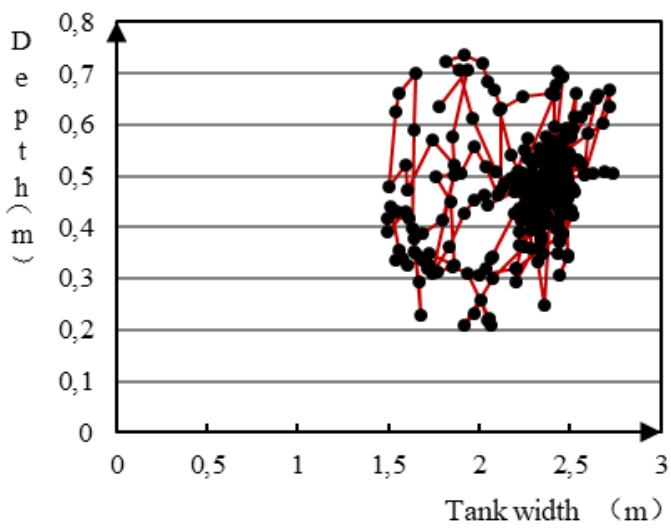

(c) Dissolved oxygen content was $2.0-3.0 \mathrm{mg} / \mathrm{L}$

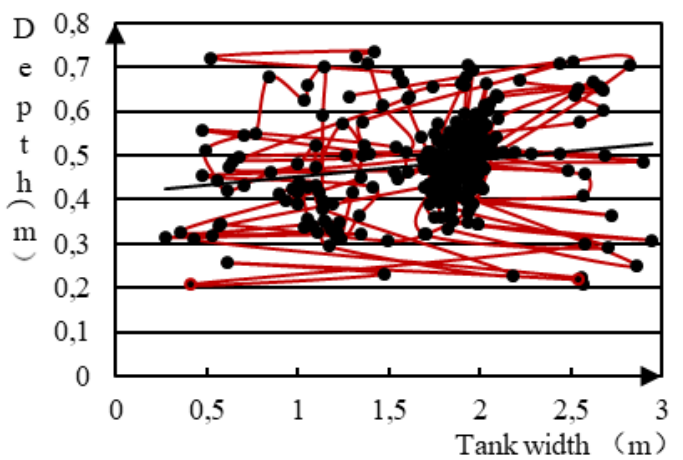

(b) Dissolved oxygen content was 4.0-5.0 $\mathrm{mg} / \mathrm{L}$

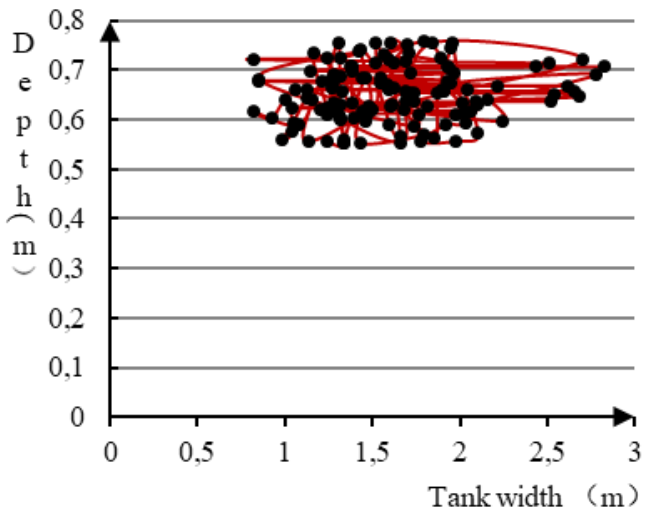

(d) Dissolved oxygen content was $0.5-1.0 \mathrm{mg} / \mathrm{L}$

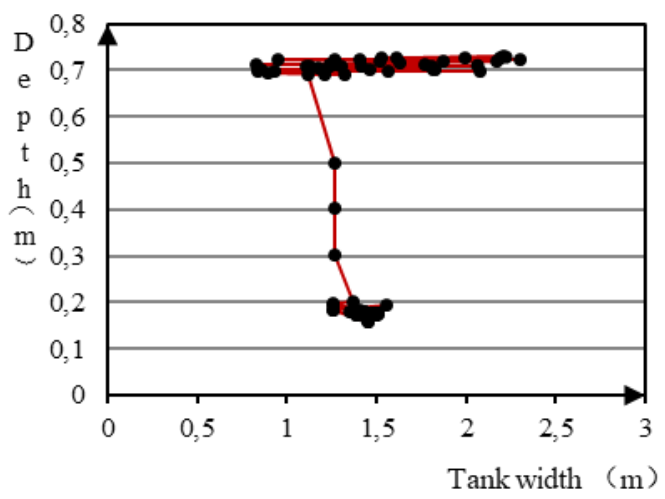

(e) Dissolved oxygen content is less than $0.5 \mathrm{mg} / \mathrm{L}$

Figure 5. Two-dimensional behavioral trajectories in the change process of dissolved oxygen content in water

2) The dissolved oxygen content was $4.0 \mathrm{mg} / \mathrm{L}-6.0 \mathrm{mg} / \mathrm{L}$ in mesotrophic stage. The carp showed short-term avoidance behavior and gathered in one place (Fig. 5b). After a period of adaptation to the water environment, the original trajectories were restored. When the dissolved oxygen content dropped to $4.0 \mathrm{mg} / \mathrm{L}$, their respiratory rate began to increase. 
3) The dissolved oxygen content was $2.0 \mathrm{mg} / \mathrm{L}$ to $4.0 \mathrm{mg} / \mathrm{L}$ in light eutrophic stage. The carp was far from the source of pollution and stayed at a certain place for a long time (Fig. 5c). They reacted slowly to external disturbances. When dissolved oxygen content was reduced to $2.0 \mathrm{mg} / \mathrm{L}$, carp breathe faster and excreted a sticky adhesive for self-protection. Occasionally, the head of carp floated on the water surface at a 45-degree angle, and then they dived into the water.

4) The dissolved oxygen content was $0.5 \mathrm{mg} / \mathrm{L}-2.0 \mathrm{mg} / \mathrm{L}$ in middle eutrophic stage. The behavioral trajectories of carp were concentrated on $15 \mathrm{~cm}$ under the water surface (Fig. 5d). They were characterized by hypoxic asphyxia, shortness of breath, and not scared by external interference. When the dissolved oxygen content was $1.5 \mathrm{mg} / \mathrm{L}$, the carp swam slowly and frequently floated on the water surface at a 45-degree angle.

5) The dissolved oxygen content was less than $0.5 \mathrm{mg} / \mathrm{L}$ in hyper eutrophic stage. At this time, the carp had a rapid breathing rate, the gill began to turn purple, and they floated on the water surface for a long time (Fig. 5e). The carp swam slowly, and then began to settle down into the water bottom after 48 hours. They died when the dissolved oxygen value was $0.2 \mathrm{mg} / \mathrm{L}$.

\section{Threshold of dissolved oxygen content when fish behavioral trajectories changed}

The experimental results showed that the rapid decline of dissolved oxygen content in water was the main factor of behavior change of fish during the process of water eutrophication. The threshold of dissolved oxygen for adult carp started to breathe hard and float was $1.5 \mathrm{mg} / \mathrm{L}$. When dissolved oxygen content dropped to $0.2 \mathrm{mg} / \mathrm{L}$, the carp began to turn over and even died.

\section{Effect of dissolved oxygen content on the swimming speed of carp}

During the process of water eutrophication, the changes of dissolved oxygen content not only leaded to the change of carp trajectory, but also directly affected the swimming speed of carp. The average swimming speed of crap at the oligotrophic and mesotrophic stage was $0.4-0.5 \mathrm{~m} / \mathrm{s}$, which was sensitive to external disturbances and vulnerable to scare. At the light and middle eutrophic stage, the swimming speed of carp was 0.2-0.3 $\mathrm{m} / \mathrm{s}$, and at that time the carp had no response to external disturbances. The carp often swam slowly on the water surface and the swimming speed was less than $0.2 \mathrm{~m} / \mathrm{s}$ at the hyper eutrophic stage.

\section{Correlation analysis between individual behavioral trajectories of carp and dissolved oxygen content in the water}

\section{Analysis of correlation between behavioral trajectories in depth and dissolved oxygen content}

According to the correlation analysis results, the correlation coefficient between behavioral trajectories at water depth and dissolved oxygen content was -0.979 (Table 2). It indicated that there was an extremely strong negative correlation between two variables, and they were significantly related at 0.01 levels (bilateral).

By data analysis, the carp behavioral trajectories at water depth had a linear negative correlation with the dissolved oxygen content. During the process of decreasing dissolved oxygen content, the trajectories of adult carp were convergent in space. In the direction of water depth, behavioral trajectories migrated from the water bottom to surface. 
Table 2. Correlation analysis between fish habitat preference at water depth and dissolved oxygen content

\begin{tabular}{cc|cc}
\hline Name & Items & $\begin{array}{c}\text { Dissolved oxygen } \\
\text { content }\end{array}$ & $\begin{array}{c}\text { Fish habitat preference at water } \\
\text { depth }\end{array}$ \\
\hline $\begin{array}{c}\text { Dissolved oxygen } \\
\text { content }\end{array}$ & Pearson correlation & 1 & $-.979 * *$ \\
& Significant (bilateral) & - & .004 \\
Fish habitat preference & $\mathrm{N}$ & 5 & 5 \\
at water depth & Pearson correlation & $-.979 * *$ & 1 \\
& Significant (bilateral) & .004 & - \\
\hline
\end{tabular}

** Significantly correlated at 0.01 levels (bilateral)

According to data of carp swimming preference, the fitting curve accords with the polynomial regression analysis type. The relationship between the position preference of carp in depth and the dissolved oxygen content was shown in Fig. 6. The formula of the fitting relationship was:

$$
\begin{gathered}
H=-0.0022 \mathrm{~d}^{3}+0.0294 \mathrm{~d}^{2}-0.1523 d+0.7601 \\
R^{2}=0.9979
\end{gathered}
$$

In the formula, " $\mathrm{H}$ " is the behavioral trajectories in depth and its unit is meter; " $\mathrm{d}$ " is the dissolved oxygen content and its unit is $\mathrm{mg} / \mathrm{L} . \mathrm{R}^{2}$ is the decision coefficient, which is the square of the correlation coefficient. $\mathrm{R}^{2}$ is 0.9979 .

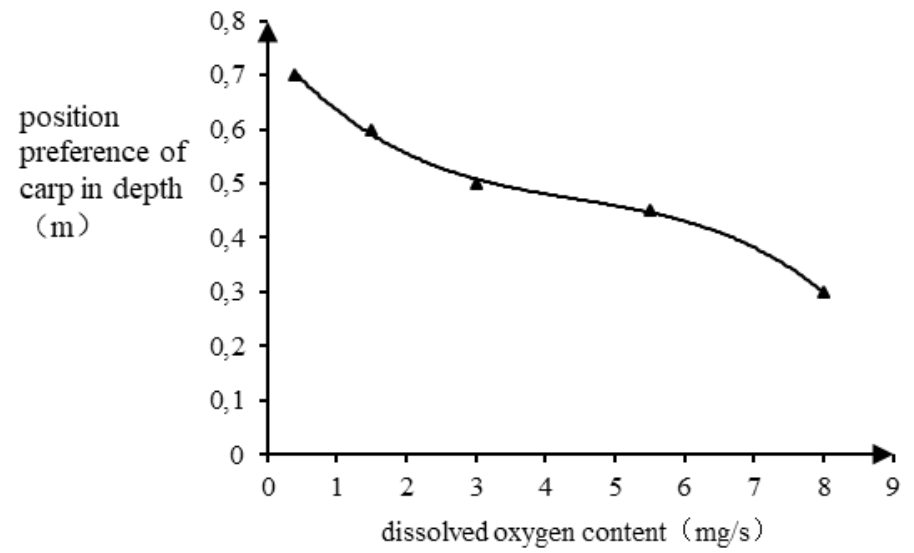

Figure 6. The relationship between the position preferences of carp in depth and the dissolved oxygen content

\section{Analysis of correlation between fish swimming speed and dissolved oxygen content}

According to the correlation analysis results of SPSS 22.0 analysis software, the correlation coefficient between carp swimming speed and dissolved oxygen content was 0.987 (Table 3). It indicated that there was an extremely strong correlation between the two variables, which was significantly correlated at 0.01 levels (bilateral). 
Table 3. Analysis of the correlation between swimming speed of carp and dissolved oxygen content

\begin{tabular}{|c|c|c|c|}
\hline Name & Items & $\begin{array}{c}\text { Dissolved oxygen } \\
\text { content }\end{array}$ & Swimming speed of carp \\
\hline \multirow{3}{*}{$\begin{array}{l}\text { Dissolved oxygen } \\
\text { content }\end{array}$} & Pearson correlation & 1 & $.987^{* *}$ \\
\hline & Significant (bilateral) & - & .002 \\
\hline & $\mathrm{N}$ & 5 & 5 \\
\hline \multirow{3}{*}{$\begin{array}{l}\text { Swimming speed of } \\
\text { carp }\end{array}$} & Pearson correlation & $.987^{* * *}$ & 1 \\
\hline & Significant (bilateral) & .002 & - \\
\hline & $\mathrm{N}$ & 5 & 5 \\
\hline
\end{tabular}

** Significantly correlated at 0.01 level (bilateral)

From the relationship between the swimming speed of carp and the dissolved oxygen content (Fig. 7), the curve fitting of two variables was polynomial regression analysis type. On the basis of correlation analysis, the formula of linear fitting relationship was:

$$
\begin{gathered}
V=-0.0017 \mathrm{~d}^{2}+0.0562 d+0.1201 \\
R^{2}=0.982
\end{gathered}
$$

In the formula, " $\mathrm{V}$ " is swimming speed of carp and its unit is $\mathrm{m} / \mathrm{s}$; " $\mathrm{d}$ " is the dissolved oxygen content and its unit is $\mathrm{mg} / \mathrm{L}$. $\mathrm{R}^{2}$ is 0.982 .

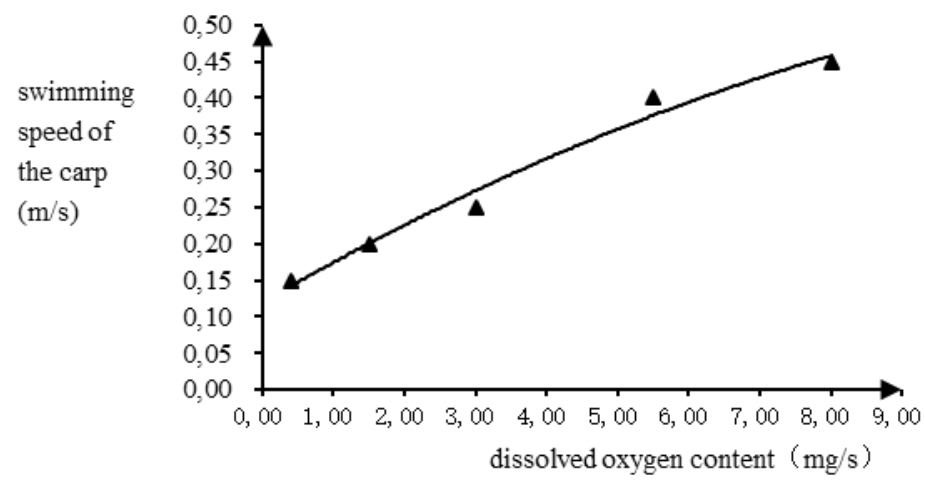

Figure 7. The relationship between the swimming speed of carp and the dissolved oxygen content

It can be seen from the above analysis that the swimming speed of adult carp was highly correlated with dissolved oxygen content. The greater dissolved oxygen content declined, the more adult carp prefer to swim to water surface, and the slower swimming speed. The obvious changes in the individual behavioral trajectories of fish indicated the variation of water quality. Therefore, the effective evaluation of environmental quality of water body was realized by monitoring fish individual behavior trajectories. 


\section{Causes Analysis of decreasing of dissolved oxygen content in the process of water eutrophication}

The amount of dissolved oxygen content in water is an important factor affecting the growth and reproduction of aquatic plants and organisms. The dissolved oxygen content mainly derives from oxygen releasing from the photosynthesis of aquatic plants and the air. When the water is contaminated by organic pollutants especially, the anaerobic bacteria will multiply and consume oxygen in the water. At this time, the water quality will be deteriorated due to the organic matter decay and decomposition if the oxygen in water is not supplemented in time. In the process of water eutrophication, the continuous reduction of dissolved oxygen content in water is the main factor for fish to change behavior. The main reasons are as follows:

1) The effect of water temperature and pressure on dissolved oxygen. The dissolved oxygen content in the water will decrease as the water temperature increases, and vice versa. The decrease of air pressure will reduce the solubility of oxygen and result in hypoxia in water.

2) The respiration of phytoplankton and aquatic organisms, oxygen demand in sediment, and oxygenation of nitrogen compounds will consume oxygen in the water. In addition, in the process of water eutrophication, algae and plankton will rapidly propagate and cover the water surface, which prevents the oxygen in the air from entering the water, and also hinders the formation of photosynthesis in aquatic plants. Therefore, oxygen in the water cannot be replenished, causing water quality deterioration.

3) There is a lot of organic matter in the water. The decomposition process of organic matters under the action of aerobic bacteria usually consumes a large amount of oxygen. Therefore, in the process of water eutrophication, the reproduction and death of algae and plankton will consume a large amount of oxygen and result in hypoxia.

4) Oxidation of inorganic substances. The oxidation will consume a large amount of oxygen when inorganic substance such as hydrogen sulfide or nitrite is present in the water.

5) A large number of aquatic organisms die because of oxygen deficiency during the state of hyper eutropher. They sink into the bottom of lake after death and are decomposed by the microorganism. There's less oxygen in the water because microorganism consume a large amount of oxygen during the decomposition.

\section{Conclusion}

At present, most of the evaluation indicators of water eutrophication status only contain the total phosphorus, total nitrogen, chlorophyll-a, permanganate index and transparency in water, but ignore the demand for dissolved oxygen in aquatic plants and aquatic organisms. Through experimental research, it was found that in the process of water eutrophication, the influence of these evaluation indicators on the changes of fish ecological behavior was not obvious. However, the level of dissolved oxygen was the main factor that directly leaded to the changes of fish behavioral trajectories and even death.

Therefore, from the perspective of aquatic eco-environmental factors and fish ecological behavior, it is suggested that add the dissolved oxygen and individual fish behavioral trajectories as biological indicators based on the original water 
eutrophication evaluation system to evaluate the water ecological restoration effect and ecological health status. It can more effectively evaluate the current status of the water ecological environment. The topic will be carried out as follow-up study in the future.

Acknowledgements. This research was financially supported by Research on Fish Individual Behavior Monitoring Technology and its Application in Fish Way and Reservoir Engineering (Grant No. 201405) and Guangxi Science and Technology Plan Project Funding (Grant No. Guike AD18126007).

\section{REFERENCES}

[1] Cai, D., Li, R. (2012): Research on Fish Habitat Based on Acoustic Fish Tracking System. Journal of Convergence Information Technology 7(23): 195-201.

[2] Dai, H., Chang, Z., Yu, N. (2015): Introduction to data mining. - Tsinghua University Press.

[3] Everson, I., Taabu-Munyahob, A., Kayandac, R. (2013): Acoustic estimates of commercial fish species in Lake Victoria: moving towards eco system-based fisheries management. Fish Res 139: 65-75.

[4] Gong, L. (2006): The studies on the effects of suspended sand on the algal growth in the eutrophic water of the Three Gorges Reservoir. - Southwest University.

[5] Hollo, T, Watson, B. M., Johnston, S. V., Devlin, R. H. (2017): Behaviour of growth hormone transgenic coho salmon Oncorhynchus kisutch in marine mesocosms assessed by acoustic tag telemetry. - Journal of Fish Biology 90(4): 1660-1667.

[6] Huang, Y. (2014): Research on early-warning of water quality by monitoring behavioral responses of zebrafish (Danio rerio) to acute stress. - Xian University of Architecture and Technology.

[7] Huang, Y., Zhang, J., Han, X., Huang, T. (2009): Vision-based real-time monitoring on the behavior of fish school. - Acta Scientiae Circumstantiate (2): 398-403.

[8] Huang, Y., Chen, X., Yuan, F. (2017): The video monitoring system of water quality based on stress behavior analysis. - Fish Journal of Xiamen University (Natural Science) 56(4): 584-589.

[9] Jiang, D. (2015): Fish montion tracing technology using video images. - Journal of Zhejiang Ocean University (Natural Science) 34(2): 112-118.

[10] Kang, I. J., Moroishi, J., Nakamura, A. (2009): Biological Monitoring for Detection of Toxic Chemicals in Water by the Swimming Behavior of Small Freshwater Fish. - J. Fac. Agr, Kyushu Univ. 54(1): 209-214.

[11] Liao, Y. (2012): The fish early-warning technique of water quality based on computer vision. - Ningbo University.

[12] Luo, W., Li, H., Mu, H. (2009): Water Environment Protection. - China Water \& Power Press.

[13] Papadakis, V. M., Papadakis, I. E., Lamprianidou, F., Glaropoulos, A., Kentouri, M. (2012): A computer-vision system and methodology for the analysis of fish behavior. Aquacultural Engineering 46: 53-59.

[14] Pinnix, W. D., Nelson, P. A., Stutzer, G. (2013): Residence time and habitat use of coho salmon in Humboldt Bay, California: an acoustic telemetry study. - Environ Biol Fish 96: 315-323.

[15] Romine, J. G., Perry, R. W., Johnston, S. V. (2014): Identifying When Tagged Fishes have been Consumed by Piscivorous Predators: Application of Multivariate Mixture Models to Movement Parameters of Telemetered Fishes. - Animal Biotelemetry, 2(1): 3.

[16] Sakalli, S., Giang, P. T., Burkina, V. (2018): The effects of sewage treatment plant effluents on hepatic and intestinal biomarkers in common carp (Cyprinus carpio). - Science of The Total Environment 635: 1160-1169. 
[17] Schultz, A., Kumagai, K., Bridges, B. (2015): Methods to Evaluate Gut Evacuation Rates and Predation Using Acoustic Telemetry in the Tracy Fish Collection Facility Primary Channel. - Animal Biotelemetry 3(1): 13.

[18] Skalski, J. R., Steig, T. W., Hemstrom, S. L. (2012): Assessing compliance with fish survival standards: A case study at Rock Island Dam, Washington. - Environmental Science \& Policy 18: 45-51.

[19] Steig, T. W., Johnston, S. V. (2010): Behavioral results from acoustically tagged fish using innovative techniques for analyzing three-dimensional data. - Oceans 2010 MTS/IEEE Seattle, 20-23 Sept. 2010.

[20] Teo, S. L. H., Sandstrom, P. T., Chapman, E. D., Null, R. E., Brown, K., Klimley, A. P., Block, B. A. (2013): Archival and acoustic tags reveal the post-spawning migrations, diving behavior, and thermal habitat of hatchery-origin Sacramento River steelhead kelts (Oncorhynchus mykiss). - Environ Biol Fish 96: 175-187.

[21] Wu, S. (2017): A practical tutorial on data mining. - Beijing: Tsinghua University Press.

[22] Xu, Z., Jiang, Y. (2009): Lake Eutrophication Assessment: Comprehensive Water Quality Identification Index. - Journal of Tongji University (Natural Science) 37(8): 1044-1048.

[23] Yan, P., Tan, J., Gao, Z., Dai, H., Shi, X., Huang, T. (2018): The analysis of fish movement behavior in vertical slot fishway based on video tracking. - Acta Hydrobilogica Sinica 42(2): 250-254.

[24] Zhang, W. (2012): Research on key technologies of video online monitoring of fish behavior. - Zhejiang University of Technology.

[25] Zhou, H. (2009): Research on computer vision — based fish movement behavior monitoring system. - Zhejiang University of Technology.

[26] Zhu, Y. J., Liu, Y., Hu, C. Y. (2018): Swimming behavior and metabolism responses of juvenile grass carp under the exposure of water-borne lead $(\mathrm{Pb} 2+)$. - Chinese Journal of Ecology 37(5): 1426-1431. 